\title{
First-Year Student Experience - Using Digital Media for Teaching and Learning amid COVID-19 Pandemic at a Rural-Based Campus
}

\author{
Judith Buhle Dlamini*, Gedala Mulliah Naidoo \\ Faculty of Arts, University of Zululand, South Africa
}

Received November 22, 2021; Revised December 28, 2021; Accepted February 8, 2022

\section{Cite This Paper in the following Citation Styles}

(a): [1] Judith Buhle Dlamini, Gedala Mulliah Naidoo, "First-Year Student Experience - Using Digital Media for Teaching and Learning amid COVID-19 Pandemic at a Rural-Based Campus," Universal Journal of Educational Research, Vol. 10, No. 3, pp. 195 - 204, 2022. DOI: 10.13189/ujer.2022.100302.

(b): Judith Buhle Dlamini, Gedala Mulliah Naidoo (2022). First-Year Student Experience - Using Digital Media for Teaching and Learning amid COVID-19 Pandemic at a Rural-Based Campus. Universal Journal of Educational Research, 10(3), 195 - 204. DOI: 10.13189/ujer.2022.100302.

Copyright $\odot 2022$ by authors, all rights reserved. Authors agree that this article remains permanently open access under the terms of the Creative Commons Attribution License 4.0 International License

\begin{abstract}
The coronavirus pandemic (COVID-19) brought higher education institutions globally to a standstill as lockdown restrictions were instituted to curb the spread of the virus. Many institutions were obligated to transform from face-to-face to virtual teaching and learning digitally. This move made digital media become a driving force for virtual learning. Students who have never used digital media for learning had to switch overnight to virtual learning; this transit placed them at a disadvantage. This paper examined the first-year students' experience on the use of digital media for learning and other disparities faced during the urgent transit to digital transformation. A qualitative observation approach was first used to gather information from a few respondents. In the quantitative approach, questionnaires were used to gather valuable feedback from respondents. A convenience sampling method was necessary due to lockdown restrictions. The paper was conceptualized using a Technological Acceptance Model (TAM) and Two-way Communication Model (TCM). The findings revealed that first-year students experienced challenges such as lack of access to computers, data, and poor network connectivity. The findings also revealed a user problem on computers and Moodle that was essential for virtual learning. This paper recommends various plausible solutions to be explored by higher education sectors in assisting first-year students to transit to digital learning and close the digital divide gap.
\end{abstract}

Keywords COVID-19, Digital Media, Digital
Transformation, Digital Divide, Virtual Learning, Teaching \& Learning

\section{Introduction}

The COVID-19 pandemic has pushed the South Africa education system to embrace digital learning rapidly. Digital learning involves online learning using ICTs and the internet. Students in basic education are familiar with a traditional classroom setup. According to Black [1], traditional classroom teaching takes place in a synchronous environment with a key benefit of face-to-face communication between a learner and a teacher. First-year students at university have expected to be in a similar classroom environment engaging the lecturer face-to-face. This expected interaction did not materialize due to lockdown restrictions.

Worldwide, teaching and learning practices have been transformed amid COVID-19 restrictions to curb the spread of the virus. As mentioned before, higher learning institutions had to change and adopt the use of ICTs such as digital media in their teaching and learning. Digital media refers to different types of media that use electronic devices for the dissemination of information in the form of sound, data, audio, or video. Maryville University [2] agrees that digital media may be presented in various systems such as 
videos, articles, advertisements, music, podcast, audiobooks, virtual reality, or digital art. Furthermore, every time one uses gadgets such as computers, cellphones, or tablets, accessing online services such as social media, email, web-browser apps, and websites, one consumes digital media.

Digital media has created an online space for the university to communicate with students and vice versa. New technologies and social media developments have created opportunities for organizations to interact with their clients in a new and creative way [3]. Furthermore, those who understand and welcome this new way of interaction, receive a reward of forming better relationships with greater loyalty from their clients. Therefore, institutions and students must embrace the new technologies for interacting with each other in platforms for teaching and learning like Moodle. However, the university must ensure that its clients (the student) have the necessary gadgets and internet access to participate in digital media platforms off-campus.

\section{Problem Statement}

The COVID-19 pandemic disrupted higher education institutions (HEIs) in South Africa to make drastic changes in the teaching and learning process. Lockdown restrictions made it impossible to maintain the face-to-face form of lesson delivery. First-year students had to face the situation of coming from a traditional learning environment to a digital media environment. First-year students had to adjust their mindset overnight and embrace for the first time a virtual classroom. With campuses closed, students could no longer have access to campus infrastructures such as the library, computer labs, and internet access. Students from rural communities face further challenges with poor or no connectivity and financial shortages. To ensure teaching and learning continues, HEIs had to become digitally compliant. Adopting digital media platforms in teaching and learning amid the COVID-19 pandemic seemed applaudable on paper. However, the realities that unfolded after its implementation brought a clear picture of the shortcomings that still needed to be addressed. Therefore, the paper focused on first-year students' experience in using digital media in teaching and learning during the lockdown.

\section{Aim of the Research}

The paper aims to examine the digital divide among first-year students and their experience using digital media off-campus for learning.

\section{Objectives of the Research}

1. To evaluate first-year students' experience using digital media while studying off-campus.
2. To evaluate possible solutions that can be implemented to help first-year students to adapt using digital media for learning during the lockdown.

\section{Research Questions}

1. What are the experiences of learning off-campus using digital media for first-year students?

2. What solutions can be developed to help first-year students to adapt to using digital media for learning while in lockdown?

\section{Literature Review}

As technologies started to emerge within the different sectors of society, higher education also started to embrace technology through the mediums of Information Communication Technologies (ICTs). It has been observed over a period how technology started to be integrated into different areas of life, including higher education sectors of teaching and learning. According to Mdlongwa [4], the $20^{\text {th }}$ century came with several technological developments such as the ever-growing use of ICTs from all walks of life, from the workplaces, sports, schools, and on personal and social levels of life. Students began to have access to the internet and computers at schools. Evans et al. [5] postulate that with the arrival of the internet and access to it in the 1990s, modern e-learning arose and became recognized in most educational institutions and other sectors.

Integrating ICTs into teaching and learning came with numerous advantages for both the lecturer and the students. It has been emphasized that the introduction of ICTs into the school curriculum became an advantage for students as it enabled them to become creators of knowledge, for example, by researching an assignment on the internet and then having to present it on a PowerPoint presentation [4]. Most higher education institutions in South Africa began to embrace a blended learning approach. However, you still have universities that continued with a traditional classroom approach of teaching and learning but incorporated educational technology and online learning on-campus activities and various forms or blending such as the use of learning management systems like the Blackboard and Moodle [5]. According to Black [1], the traditional classroom practice has been in operation for decades in South Africa, and it is not a bad practice since it has the following advantages:

- learners develop enthusiasm from the educator as well as from their classmates,

- education is more improved when students work in teams other than individually,

- working in teams enhances participation in education,

- when one student shares their ideas and gives feedback to other reactions from classmates, thinking is improved, and understanding deepens. 
South African universities have experienced an emergent evolution from face-to-face to online learning due to the rise of COVID-19. To curb the spread of infection, higher education institutions had to transform from face-to-face class teaching and move to virtual learning through the channels of digital media. This mode of teaching and learning relies much on the use of computers and the internet to connect students to lecturers and educational resources. Cranfield et al. [6] suggest that this disruption placed traditional universities in a predicament since they did not have the essential infrastructure or support services to attend to the transformed teaching landscape. Moreover, lectures had to alter their teaching material for online learning without sufficient training or support, and assessment approaches had to be modified for online application in contrast to the standard traditional examination setup with invigilators to ensure credibility.

\section{Digital Learning Divide}

The digital divide refers to the gap between those who have access to technology such as a computer, tablet, or smartphone and the internet and those without access. Digital inequality exists between people who have access to modern information and communication technology devices and those who lack access [7]. During the pandemic, a lot of people lost their jobs which meant difficulties for parents to support their children in tertiary with the technological gadgets and data to access the internet to participate in virtual learning. Ong [8] agrees that the digital learning divide also emanates from financial issues because of unemployment or loss of jobs due to the pandemic of households with low-income earners.

Thus, Moore et al. [9] state that the digital divide in education becomes more evident when students who are working from home experience challenges such as technological deficient issues or poor networks, which deprive them of engaging in online learning. When students attend lectures on campus, no one lacks access to modern information and communication technology devices because students have access to fully equipped computer labs. This makes digital learning efficient for all students regardless of their background (from rural or urban areas or poor communities) and closes a digital divide gap. The digital learning divide is not new; however, COVID-19 restrictions in place to curb the spread of the pandemic meant that students from traditional universities such as the University of Zululand (UNIZULU) had to transit urgently from in-class learning to virtual learning from home.

Students from UNIZULU are both from urban and rural areas of South Africa. The digital divide is usually obvious between those living in urban areas and those living in rural areas; also, between socioeconomic groups; between less economically developed countries and more economically developed countries; between the educated and uneducated population [7]. The definition above asserts that in most cases, you will find that those living in the rural areas have poor network coverage or none. Access to gadgets such as computers or information and communication devices is limited in rural areas due to poverty and network connectivity compared to urban areas. Dube [10] coincided by emphasizing that students from the rural areas faced incomparable difficulties adjusting to the new mode of life and digital learning because rural areas in South Africa, mostly lace the social and economic feasibility required to sustain technological improvement. Most learners from the cities are already using digital learning, but learners in rural areas are still on the traditional face-to-face learning [10]. The University of Zululand is in the rural banks of KwaZulu-Natal province, providing service to most locals within the province. The students from rural areas will be coming from secondary schools that have no digital learning in place, no computer labs, or internet access. Therefore, COVID-19 and the employment of digital learning have expanded the challenges experienced by students, especially from rural areas [10]. This has led to university students not fully embracing the transition to virtual learning as they felt that it was designed to accommodate the rich and to disadvantage the poor further [11].

The rise of COVID-19 impacted largely on the student learning experience. According to Mpungose [12], some difficulties hinder disadvantaged students from realizing the full potential of online learning. Furthermore, students from remote areas where there is no access to the internet struggled with how they were going to access the newly introduced digital media channels for virtual learning such as Zoom, Teams, Big Blue Button, and Moodle that had the module activities [12]. The common face-to-face interaction with lecturers and fellow students on campus changed overnight due to the coronavirus pandemic leaving disadvantaged students in a predicament as they were still expected to attend online lectures, submit assignments, write tests and examinations online. Hence, the lack of full access to technologies such as computers or the internet leads to missed lectures, failure to access module materials, and challenges in completing required assignments or assessments [8]. Certain privileges such as free access to a computer lab, internet, library, lecturer halls which provide a private space for a student to learn, were no longer available. According to Cranfield [6], students also faced challenges with a transition from face-to-face to online learning because they no longer had the time and space to study at home and compared to when they are on campus; some students do not have access to computer/smartphones or internet access that is required to access study material for online learning. The issue of disadvantaged students needs to be addressed to allow effective use of digital learning among all students. It has been noted that many institutions of higher learning are making efforts to support students by offering free access to online learning platforms. $\mathrm{Li}$ and Lalani [13] concur that 
in response to the significant demand for online learning, the education sector is offering free access to online learning platforms. Providing free access to online learning platforms is good; however, all students must also be equipped with laptops or computers, data, live in areas with network connectivity to access these online learning platforms. Moreover, the unplanned and rapid move to online learning due to COVID-19 restrictions may result in poor user experience due to the lack of the digital divide and digital learning [13].

\section{Conceptual Framework}

According to Adom et al. [14], the importance of applying a theoretical and conceptual framework provides a road map that explains the research and allows it to be grounded theoretically. This provides the overall aim is for using two frameworks that will make the findings of research more meaningful. This further ensures that theoretical constructs in the research field are acceptable and ensures generalizability. Moreover, it also assists by stimulating your research, ensuring knowledge is increased, which provides direction to the research inquiry [14]. The following two models were conceptualized in the conceptualizing of this research, the Two-way Communication Model and Technology Acceptance Model.

\section{Two-way Communication Model}

Communication is used by both lecturers and students, and for it to be effective, there must be a proper process in place that will promote effective communication. The two-way communication model provides a clear process of how effective communication can be achieved.

The two-way Communication Model is the process that is used in human communication, and this process is adapted when we introduce a channel or a medium such as technology. The model constitutes of the following significant elements of a communication process: information source, transmitter, channel, receiver, destination, and noise [16]. The information source or sender in this study would be the lecturer who will encode the message (module outline, study guides, module content, assignments, assessments dates). Message can be transmitted using various digital communication channels (social media platforms, blogs, Moodle, and even WhatsApp) to accommodate students even in remote areas. First-year students will be the receiver who will decode the message. The process of effective communication is vital to the teaching and learning experience of first-year students especially using digital media during this COVID-19 lockdown. This model illustrates the process of communication between lecturer and students, and since teaching and learning have become online learning, it would require a conducive virtual internet connection to establish and maintain communication throughout the engagement, as illustrated in Figure 1. The lecturer must be able to communicate, and the students must respond; this requires form roles to be switched. When students respond to the message from the lecture, it is called feedback. They could be communicating their lack of understanding of the content or submitting assignments. Thus, when students provide feedback that is where roles are switched as they become the sender. The noise interferences in the communication process interfere with the message and feedback, and in the instance of first-year students, that could be lack of internet access, located in areas with no network, lack of gadgets to connect online. Such interferences disrupt the communication process between the lecturer and first-year students during online learning. Effective communication is achieved when both the lecturer and student can understand each other. Therefore, institutions of higher learning must establish various approaches of communication channels to reach students even in remote areas for effective online learning for first-year students.

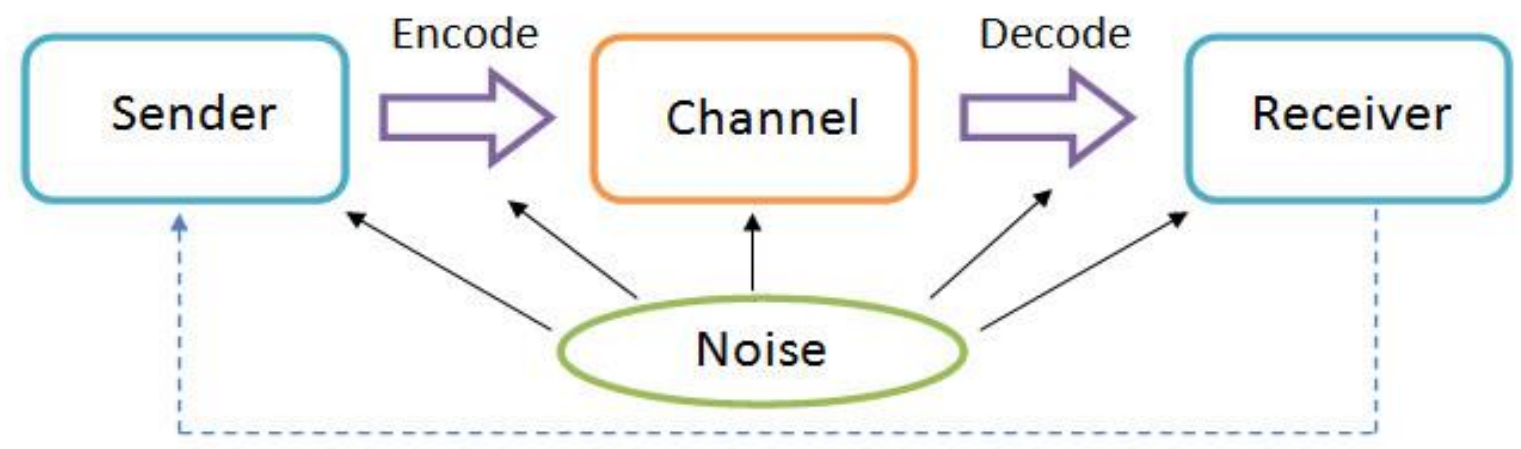

Feedback

Source: adapted from [15]

Figure 1. Two-way Communication Model 


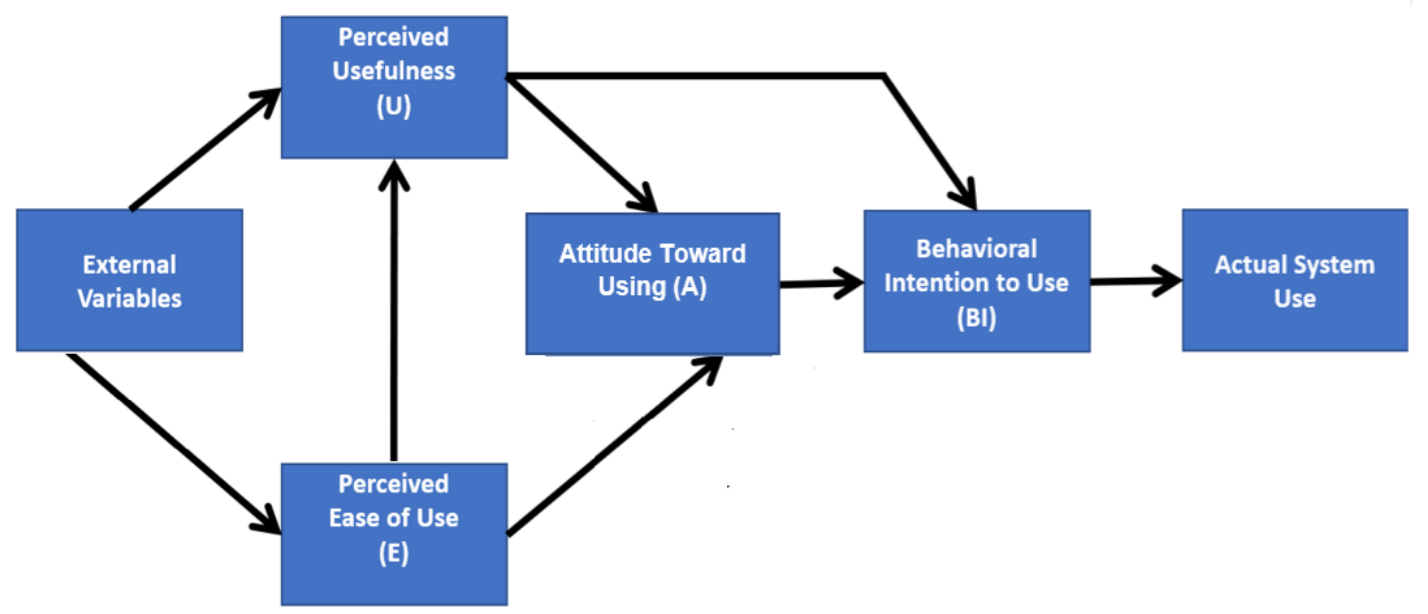

Source: adapted from Davis et al. [17]

Figure 2. Technological Acceptance Model

\section{Technological Acceptance Model}

To define the behavior of computer usage, Davis et al. [17] developed a Technology Acceptance Model (TAM). The TAM model is used to access how users come to accept and use technology. The TAM is based on the following concepts: "Perceived Usefulness (PU)" and "Perceived Ease of Use (PEOU)", which influence the attitude of a user [18]. The external variables that students face are diverse, and this affects their Perceived Usefulness and Perceived Ease of Use on digital media that is used to access online learning. The first-year students have come to university with a firm grounding teacher-to-learner experience, and to some degree, they were expecting to have a lecturer-to-student experience at university. However, COVID-19 lockdown restrictions have disrupted this traditional form of teaching. The engagement process changed, and universities have switched to online learning. The university and the first-year students relate to the TAM concept of PU and know that digital media and its devices are useful for online learning. Many of the first-year students are digital natives [19], so they can easily use digital media and devices for their learning. Some are digital strangers who will need time to simulate and be at the proficiency and in a short space of time can fully function in the concept of PEOU [20]. The first-year students' attitude of use can be affected if they are prevented from fully using digital media, especially when there is no digital device and internet connectivity. By having this in place and with the proper training, their behavior is positively motivated, which finally results in the actual use of digital media and the devices such as laptops and learning management systems for online learning. Lecturers and students should be provided with ICT support on the use of technological devices and software applications that are used for online teaching and learning.

\section{Research Methodology}

This study adopted a mixed-method research design; it is a combination of both qualitative and quantitative research of data in a single study that provides an advantage of more validity and reliability on the findings of research [21]. Dawadi et al. [22] postulate that one of the mixed methods designs which are exploratory sequential design is in three phases: the researchers first gather qualitative data from a small group and analyses it; this builds to a quantitative data collection from a large group and analysis; the last phase is the interpretation of the results. Moreover, the qualitative data determines the type of questions asked so that data can be collected.

The desktop research approach surveyed similar research done in this area which contributed toward the literature review providing a better understanding of the study. Moreover, the qualitative observation was used to gather information from a small group of first-year students in the Department of Communication Science. Thus, Hour [23] concurs that a qualitative observation provides emphases on collecting data from a small number of participants to dig out details from each participant.

To support the qualitative observation summary, the study also employed a quantitative approach where questionnaires were used to gather valuable feedback from respondents. Apuke [24] asserts that quantitative research methods include surveys in the form of sampling questionnaires for gathering information from respondents under the study to analyze and better understand their behavior or characteristics. Moreover, Dawadi et al. [22] affirm the following advantages for using both research methods: linking qualitative with quantitative data results in presenting research problems in a meaningful explanation. The quantitative method enables the researcher to collect data from many participants and generalize the findings of a wider population; on the other 
hand, the qualitative approach provides a deeper understanding of the problem being investigated, validating the feedback provided by the participants.

Taherdoost [25] suggests that convenience sampling is a method whereby a researcher collects data from a conveniently available pool of respondents. Moreover, convenience sampling is very useful when you need to conduct research on a strict budget or experience a challenge in reaching the targeted population. Thus, convenience sampling was necessary for this paper due to the absence of students on campus because of COVID-19 restrictions. The first-year students' enrollment in the Department of Communication Science was 130 for 2021, and while the researchers provided all these students to participate, only 82 students participated.

\section{Research Ethics}

The following ethical principles were adhered to by ensuring that participants were given the right to participate voluntarily and could withdraw at any time of the study. Participants were made aware that they could ask any questions that were related to the research. The participants were made aware that their privacy is protected, and no responses can be traced back to them. The design of the questions was structured in an understandable language. The research was not biased against culture, race, or gender.

\section{Results and Discussions}

The Department of Communication Science at the University of Zululand has the following programs: Diploma in BA Intercultural, Diploma in Media Studies, and Diploma in Public Relations Management.

During the digital transformation brought about by the emergence of COVID-19, first-year students were having user problems such as how to log in on Moodle and how to use the laptops provided by the university. While other students simply did not have a computer or even a smartphone to access digital media for virtual learning. Students also experienced a problem with access to the internet because data is expensive in South Africa. Due to lockdown restrictions, campuses and residential areas that can provide students with a computer lab and internet access were closed. Students experienced network problems, load shedding problems. This resulted in late or no submission of assignments, tests and low or no attendance of virtual classes.

The following findings are derived from the voluntary online questionnaires that were distributed to first-year students:

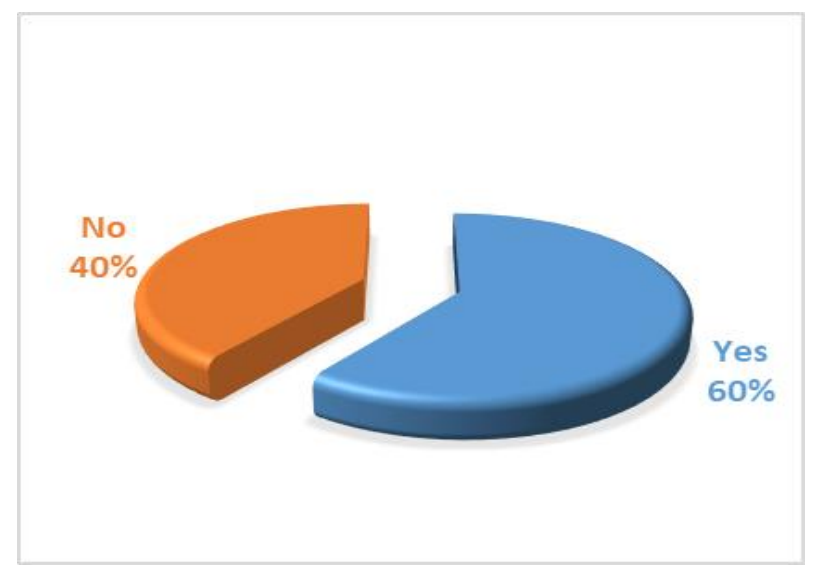

Figure 3. The university provided first-year students with laptops

The COVID-19 outbreak forced many institutions in higher education to emergently transit to online learning. That meant that students would need a computer/laptop to work on from home and a reliable internet connection. Studying from home deprives students of poor or deep rural communities of access to computer labs available on campus and access to free internet. Figure 3 postulates that about $60 \%$ of first-year students were provided with laptops by the university. On the other hand, you have $40 \%$ of first-year students who were not provided with laptops. This poses a challenge on this $40 \%$ of students without laptops as they are expected to study online from home.

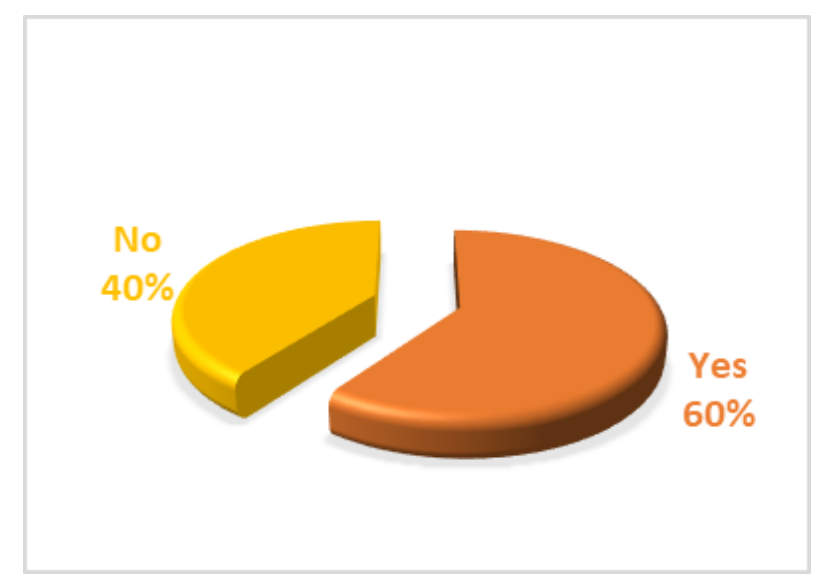

Figure 4. The university provided first-year students with sufficient training during the orientation on how to use computers/laptops

During registration at the beginning of the year, first-year students are expected to attend an orientation. Part of the one-week orientation includes a session on how to use a computer. About $60 \%$ of first-year students agree that the training during orientation week on how to use computers or laptops was sufficient. However, $40 \%$ of students are still not comfortable with using a computer. These are the same students expected to attend lectures via Moodle BBB, conduct research, study, and access online services using a computer or tablet. Although students may use a smartphone, $67 \%$ preferred accessing online services 
for their studies using a laptop/computer as it was challenging to type assignments, engage in research, and attend online lectures using their phones.

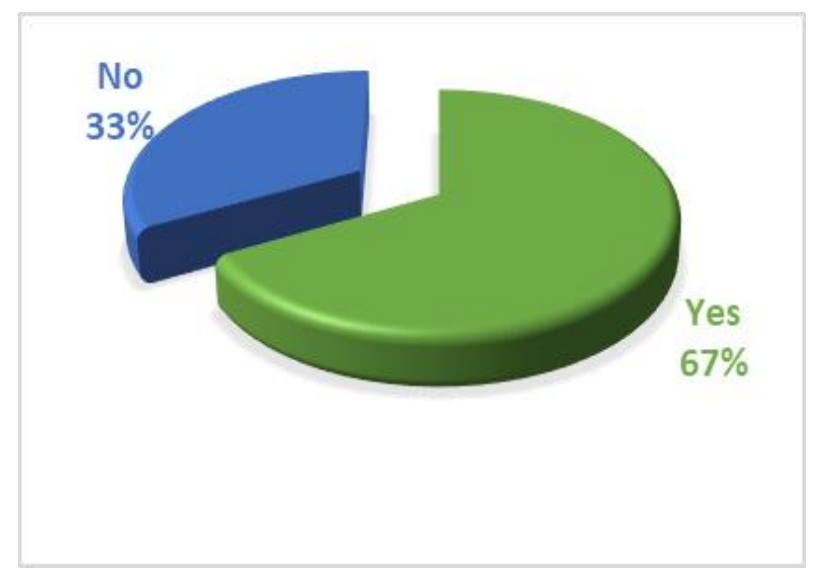

Figure 5. The university provided first-year students with sufficient training during orientation week on how to use Moodle (LMS)

This graph asserts that most students (67.1\%) had obtained good knowledge from the training on how to use (LMS) Moodle. However, knowing how to use Moodle and not having the gadget to connect to this service is a major problem for students and lecturers who want to engage with each other.

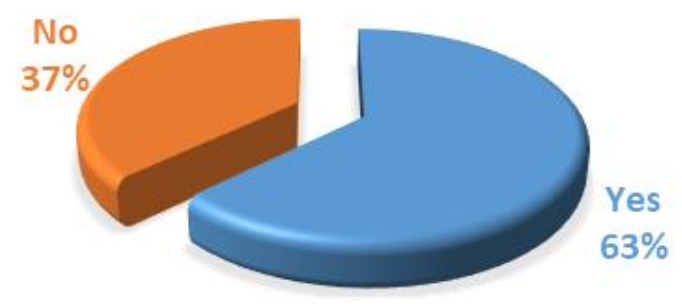

Figure 6. University provides students with free access to Moodle (LMS)

While we had the university assure the staff members that students had free access to Moodle. The findings prove otherwise as $63 \%$ of first-year students confirmed that they did not have free access to the learning management system - Moodle used by the University of Zululand.

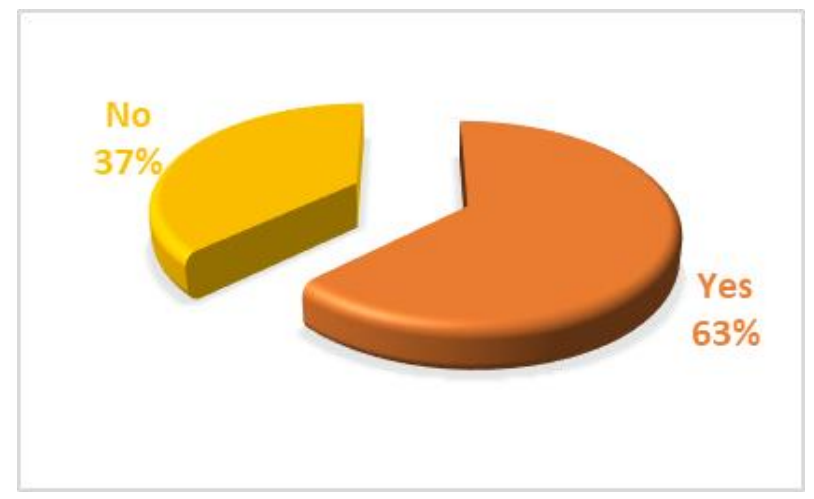

Figure 7. Experienced network problems while studying from home

In South Africa, you still have rural areas without a network or with a poor network connection. The graph confirms that about $79.3 \%$ of first-year students experienced difficulties with online learning because of network problems in their hometowns.

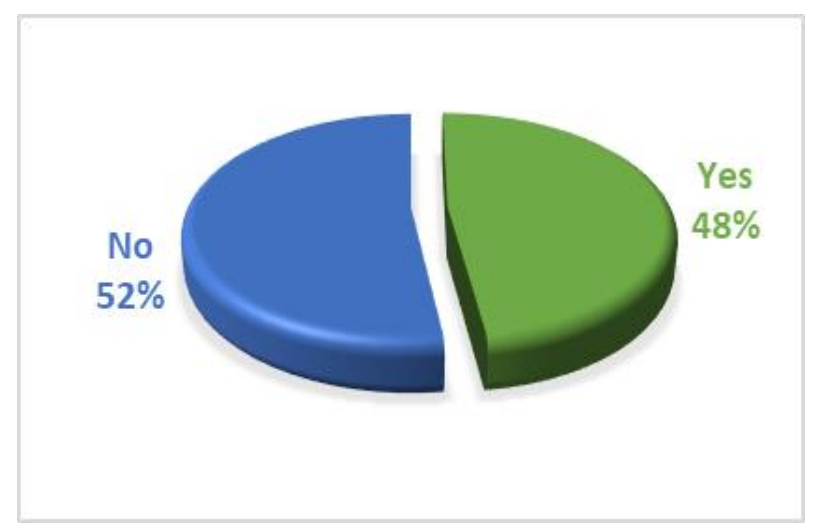

Figure 8. Students were able to provide themselves with data to connect to the internet for online teaching and learning

About $48 \%$ of first-year students were able to provide themselves with data to access the internet for online learning. However, you still have a large number of $52 \%$ who were not able to provide themselves with data to have access to the internet for online teaching and learning during lockdown restrictions.

The graph shows that lecturers from UNIZULU are mostly comfortable with LMS Moodle and WhatsApp for communication, teaching, and learning. Big Blue Button (BBB) enables lecturers to have live classes with students who are in various locations, and $72 \%$ of students confirmed that lectures are using this system. The question is: where does this leave a student without access to online services? A student without access to a computer/laptop or smartphone? A student in a location with zero network or poor network connectivity? 


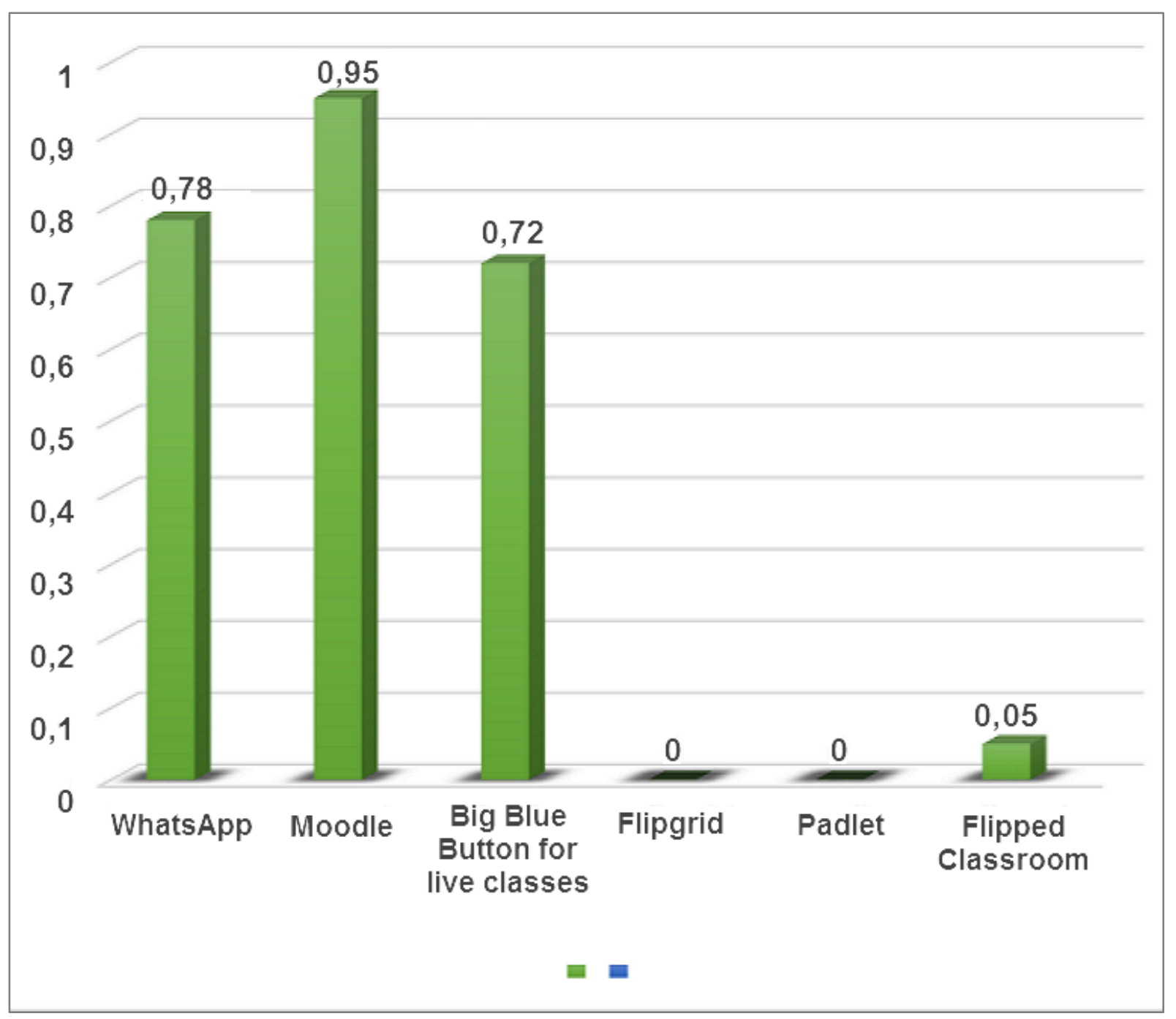

Figure 9. Digital media tools are largely used by lecturers for communication, teaching, and learning

The learnings gleaned from literature depicted the importance of the use of digital media for learning and teaching. Communicating effectively is essential; the two-way communication model and the TAM provides the conceptualization of the study, outlining that both teachers and students alike must be able to communicate with each other as described in the two-way communication model. Understanding the use of digital technology and its usefulness is also essential for learning and teaching purposes during this pandemic. The use of digital media has contributed significantly in assisting in saving the academic year.

\section{Conclusion and Recommendations}

Digital media has created an online space for the university to interact with students and vice versa amid the COVID-19 pandemic. The use of digital media enables the teaching and learning to continue regardless of the geographical space of the lecturer or student. The students have embraced the use of digital media in teaching and learning as they have made efforts to interact with their lectures. However, this experience came with several challenges for first-year students, such as the emergent transition from face-to-face learning into online learning. Such challenges threaten the academic success of students. The brief findings of this paper revealed a widening digital divide among first-year students as they transited to online learning using various digital media channels. Some of the challenges experienced by first-year students that revealed digital divided are indicated below:

- Some students had no access to technological devices such as computers or smartphones needed to participate in online learning.

- Inability to use a computer because of coming from secondary schools without computer labs; also, insufficient training face-to-face during the orientation week.

- Lack of provision of zero-rated data to access Moodle to attend online lectures and access module content as 
not all students can afford data due to the high volume of unemployment in South Africa.

- Lack of understanding of how to use learning management systems (LMS); also, insufficient training face-to-face during the orientation week.

- Students who are in rural areas with poor network connectivity or areas with no network connectivity; all these issues deprived some of the students to participate in online learning fully.

- Both higher and basic education must engage students at the secondary level and provide training and development for students to become digitally compliant.

Even though the findings revealed that there were so many challenges experienced by first-year students that hindered them from fully embracing the use of digital media for online learning; there are alternative pathways that the university, government, businesses, non-profit organizations, and local municipalities could implement to be the solution in the context of COVID-19 pandemic. In response to this crisis, the study recommends the following:

- Government and businesses should intervene to help close the gap of the digital divide by providing computers to secondary schools, not only to the rural areas of KwaZulu-Natal where the campus is based, but this should be an initiative nationwide. This will mean that the university will receive first-year students who are already computer literate and will not have a problem transitioning from face-to-face learning into online learning through various digital media channels. A plan should be in place to provide all first-year students with laptops to ensure teaching and learning for ALL students, not some students. Provision can be made through educational funding, businesses interventions for those without funding.

- Local municipalities should engage with local businesses, non-profit organizations, and the government to ensure that every municipality has not only a library but also a fully functional computer lab with free internet connectivity. This will help university students who do not have access to computers or students experiencing network problems or affordability issues.

- The use of zero-rated applications and educational websites would be helpful to assist with affordability issues.

- Discussions with data service providers should be in place to provide students with zero-rated data on learning management systems.

- First-year students need to be provided with a longer-term orientation on how to use a computer and learning management systems that the university is using for teaching and learning.

- Plans from the ICT division should be implemented to help enhance the support they provide to first-year students while they are studying off-campus due to lockdown restrictions to help curb the spread of the COVID-19 virus.

- Higher education institutions could look at making technology such as a laptop or an iPad part of a standard financial package for all first-year students in response to the digital divide and in response to ensuring that no student is left behind.

- The library department allows short to long-term loans on books; therefore, the university should consider discussions with ICT to allow short to long-term loans on laptops or iPads to students in desperate need.

The coronavirus pandemic came unexpectedly for most universities and disrupted the traditional teaching and learning of face-to-face interaction. However, the pandemic became an eye-opener for many higher education institutions to ensure that they are at the state of being prepared for possible future pandemic outbreaks. The coronavirus pandemic has also enforced digital transformation for higher education institutions. Students at this stage of learning are more than capable of handling online work and technology. So long as they are provided with sufficient training on how to use the technology and online services and provided with access to technological services and networks. Therefore, moving forth, the universities should consider not fully going back to face-to-face teaching. However, consider using more online learning and a bit of face-to-face teaching and learning. Looking at the vaccination roll-out in South Africa, students should have access to facilities in their residential areas, such as computer labs that can provide all the resources required for students to embrace digital learning fully.

\section{REFERENCES}

[1] Black, G., "A Comparison of Traditional, Online And Hybrid Methods of Course Delivery," Journal of Business Administration Online, vol.1, no.1, pp. 1-9, 2002. http://citeseerx.ist.psu.edu/viewdoc/ download?doi=10.1.1.511.6645\&rep=rep1\&type=pdf

[2] Maryville University., "What Is Digital Media?", https://online.maryville.edu/blog/what-is-digital-media/ (accessed March 12, 2021).

[3] Cleary, S., "Communication: A Hands-On Approach," 2nd ed, Juta, 2014, pp 1-438.

[4] Mdlongwa, T., "Information and Communication Technology (ICT) as a Means of Enhancing Education in Schools in South Africa: Challenges, Benefits and Recommendations," Journal of Africa Institute of South Africa, vol.10, no.80, pp. 1-8, 2012. http://www.ai.org.za/ wp-content/uploads/downloads/2012/10/No.-80.-ICTas-ameans-of-enhancing-Education-in-Schools-in-South-Afric a.pdf 
[5] Evans, J., Yip, H., Chan, K., Armatas, C., Tse, A., "Blended learning in higher education: professional development in a Hong Kong university," Journal of Higher Education Research \& Development, vol.39, no.4, pp. 643-656, 2020. https://doi.org/10.1080/07294360.2019.1685943

[6] Cranfield, D., Tick, A., Venter, I., Blignaut, R., Renaud, K., "Higher Education Students' Perceptions of Online Learning during COVID-19-A Comparative Study," Journal of Education Sciences, vol.11, no.8, pp. 1-17, 2021. https://doi.org/10.3390/educsci11080403

[7] Steele, C., "What is digital divide?", Digital Divide Council, http://www.digitaldividecouncil.com/

what-is-the-digital-divide/ (accessed June 4, 2021).

[8] Ong, P., "COVID-19 and the Digital Divide in Virtual Learning, Fall 2020", Center for Neighborhood Knowledge, https://knowledge.luskin.ucla.edu/wp-content/uploads/202 0/12/Digital-Divide-Phase2_brief_release_v01.pdf (accessed June 1, 2021)

[9] Moore, R., Vitale, D., Stawinoga, N., "The Digital Divide and Educational Equity: A Look at Students with Very Limited Access to Electronic Devices at Home", ACT Research \& Center for Equity in Learning, https://files.eric.ed.gov/fulltext/ED593163.pdf (accessed March 12, 2021).

[10] Dube, B., "Rural Online Learning in the Context of COVID-19 in South Africa: Evoking an Inclusive Education Approach," Multidisciplinary Journal of Educational Research, vol.10 no.2, pp. 135-157, 2020. DOI: 10.4471/remie.2020.5607

[11] Naidoo, G., \& Israel, C., "A Critique of Online Learning in Higher Education during the Coronavirus Lockdown Level 5 in South Africa," African Journal of Development Studies, vol.11, no.1, pp. 127-147, 2021. https://doi.org/10.31920/2 $634-3649 / 2021 / \mathrm{v} 11 \mathrm{n} 1 \mathrm{a} 6$

[12] Mpungose, C., "Emergent transition from face-to-face to online learning in a South African University in the context of the Coronavirus pandemic," Journal of Humanities and Social Sciences Communications, vol.7 no.113, pp. 1-9, 2020. https://doi.org/10.1057/s41599-020-00603-x

[13] Li., C., \& Lalani, F. (2020). World Economic Forum. Retrieved July 2021, from https://www.weforum.org/agen da/2020/04/coronavirus-education-global-covid19-online-d igital-learning/

[14] Adom, D., Hussein, E., \& Agyem, J., "Theoretical and conceptual framework: Mandatory ingredients of quality research," International journal of scientific research, vol.7, no.1, pp. 438-441, 2018. https://www.researchgate.net/pub lication/322204158_THEORETICAL_AND_CONCEPTU AL_FRAMEWORK_MANDATORY_INGREDIENTS_O F_A_QUALITY_RESEARCH
[15] Communication Theory., "Shannon and Weaver Model of Communication", https://www.communicationtheory.org/shannon-and-weav er-model-of-communication/ (accessed March 12, 2021).

[16] Businesstopia., "Shannon and Weaver Model of Communication",

www.businesstopia.net/communication/shannon-and-weav er-model-communication (accessed June 20, 2021).

[17] Davis, F., Bagozzi, R., Warshaw, P., "User Acceptance of Computer Technology: A Comparison of Two Theoretical Models," Journal of Management Science, vol.35, no.8, pp. 982-1003, 1989. https://www.jstor.org/stable/2632151

[18] Opoku, M. O., Enu-Kwesi, F., "Relevance of the technology acceptance model (TAM) in information management research: a review of selected empirical evidence," Pressacademia, vol.7, no.1, pp. 34-44, 2020. DOI: 10.17261/Pressacademia.2020.1186

[19] Prensky, M., "Digital natives, digital immigrants part 1," On the Horizon, vol.9, no.5 pp. 1-6, 2001. https://www.marcprensky.com/writing/Prensky\%20-\%20D igital\%20Natives, \%20Digital\%20Immigrants\%20-\%20Par t1.pdf

[20] Czerniewicz, L., Brown, C., The habitus of digital strangers in higher education," British Journal of Educational Technology, vol.44, no.1, pp. 44-53, 2013. http://hdl.handle.net/11427/3335

[21] Hafsa, N.E., "Mixed Methods Research: An Overview for Beginner Researchers," Journal of Literature, Languages and Linguistics, vol.58, pp.45-49, 2019. https://www.researchgate.net/publication/338751170_Mix ed_Methods_Research_An_Overview_for_Beginner_Rese archers

[22] Dawadi, S., Shrestha, S., Giri, R., "Mixed-Methods Research: A Discussion on its Types, Challenges, and Criticisms," Journal of Practical Studies in Education, vol.2, no.2, pp 25-36, 2021. DOI: https://doi.org/10.46809/jpse.v $2 \mathrm{i} 2.20$

[23] Hour, V., "Observation is Both a Qualitative and Quantitative Technique", https://www.researchgate.net/pu blication/345400251_Observation_is_Both_a_Qualitative and_Quantitative_Technique (accessed June 12, 2021).

[24] Apuke, O. D., "Quantitative Research Methods a Synopsis Approach," Arabian Journal of Business and Management Review, vol.6 no.10, pp. 40-47, 2017. DOI: $10.12816 / 0040336$

[25] Taherdoost, H., "Sampling Methods in Research Methodology; How to Choose a Sampling Technique for Research," International Journal of Academic Research in Management," vol.5 no.2, pp. 18-27, 2016. DOI: 10.2139/ssrn.3205035 